Magazine of Concrete Research Volume 68 Issue 9

Performance of in situ stitches in precast segmental bridges

Leung and $\mathrm{Au}$

\title{
Performance of in situ stitches in precast segmental bridges
}

\section{Cliff Chun Yu Leung}

Part-time lecturer and former PhD Student, Department of Civil Engineering, The University of Hong Kong, Hong Kong
Francis Tat Kwong Au

Professor, Department of Civil Engineering, The University of Hong Kong, Hong Kong

In situ concrete stitching with subsequent prestressing is often used in construction to join together precast concrete segments. An example of an application is the stitching of the approaching decks of precast segmental bridges constructed using the balanced cantilever method. The relatively narrow stitches used in segmental bridges are often provided with nominal reinforcement only. Therefore, the in situ stitch is a location of potential weakness, but relatively little work has been done in this area. In light of this, extensive experimental and numerical studies on the behaviour of precast concrete members with in situ concrete stitches have been conducted. The effects of stitch width, prestressing force, concrete strength, bonding of tendon and provision of shear keys on the performance of such members are presented in this paper. Unlike members that are continuously cast, cracking initiates along the construction joint between the precast segment and the stitch at low load levels for members with in situ stitches, while no cracking is observed elsewhere. The cracks widen extensively as the load level increases and can become detrimental to the serviceability of the members. Such members should be designed so that the joints are subject to no tension under service load.

$\begin{array}{ll}\text { Notation } \\ G_{\mathrm{c}} & \text { pre-crack shear modulus } \\ G_{\mathrm{c}, \mathrm{cr}} & \text { post-crack shear modulus } \\ q & \text { bond stress } \\ u & \text { slip of tendon } \\ \beta & \text { shear retention factor }\end{array}$

\section{Introduction}

In situ concrete stitching is often used in construction to join together precast concrete segments, with subsequent prestressing provided to strengthen the stitch when the use of a regular epoxy joint between match-cast concrete segments is not possible. An example of an application is the stitching of the approaching decks of precast segmental bridges constructed using the balanced cantilever method, which is one of the most popular methods used for bridge construction. The method essentially involves sequentially extending precast segments outwards from each bridge pier in a roughly balanced manner. A gap is needed between the last two approaching segments around the midspan to facilitate erection. In situ concrete is then cast to 'stitch' the segments together, thus making the bridge deck continuous.

The width of the in situ stitch is usually no more than 1-2 m. A common practice is to construct a narrow stitch (100-200 mm wide) so that longitudinal non-prestressed reinforcement can be avoided, and thus the stitch is only provided with transverse reinforcement and longitudinal continuity tendons that usually run through the bottom region of the stitch. Such a practice makes the stitch capable of sustaining considerable sagging moment, but its hogging moment capacity and shear resistance are only nominal. Failure of these stitches can occur under exceptional scenarios, especially when the hogging moment is high.

Experimental studies on the construction joints of segmental bridges have been conducted previously. The work by Buyukozturk et al. (1990), Hewson (1992), Issa and Abdalla (2007), Koseki and Breen (1983), Turmo et al. (2006) and Zhou et al. (2005) involved loading tests on joint specimens of local scale. Tests on a full-scale segmental bridge model to examine the behaviour of its joints have also been performed (Megally et al., 2003; Moreton, 1981; Takebayashi et al., 1994; Turmo et al., 2005). However, the joints studied were either dry or epoxy joints between precast segments, not in situ concrete stitching joints. As relatively little research has been done in this area, the understanding of the actual behaviour of In situ stitches is limited.

In light of this, extensive experimental and numerical studies were carried out to investigate the behaviour of members joined by in situ concrete stitches. The experimental study involved a series of loading tests on specimens comprising precast segments with or without in situ concrete stitches. The stitch was subject to (i) pure bending moment, (ii) pure shear or (iii) their combination. Various parameters were varied to examine their effects on the load-deflection relationship, the 
strength and the failure mode of the specimens. Further parametric study by finite-element analysis was conducted to examine the effects of additional parametric values not tested.

In this paper, the effects of stitch width, prestressing force, concrete strength, bonding of the tendon and the provision of shear keys on the load-deflection response obtained experimentally and numerically are presented. The effect of prestressing force on crack-width development is also examined. Such findings can have an impact on the design of bridges with In situ stitches.

\section{Experimental programme}

The experimental programme involved loading tests on 15 beam specimens of different configurations. A specimen was either composed of two precast units joined together by a 50 or $100 \mathrm{~mm}$ wide in situ concrete stitch, or one unit match cast against a precast unit. The specimens were prestressed by either bonded or unbonded tendon(s), and hence hereafter they are referred to as the 'bonded' and 'unbonded' specimens, respectively. The specimens were divided into three series $\mathrm{M}, \mathrm{V}$ and $\mathrm{MV}$, in which the in situ stitch was subject to pure bending moment, pure shear, and a combination of moment and shear, respectively.

\section{Configuration of the specimens}

Schematic diagrams of the specimens are shown in Figure 1. All specimens were $1400 \mathrm{~mm}$ long and rectangular in section (200 $\mathrm{mm}$ deep and $150 \mathrm{~mm}$ wide). To produce the desired internal force at the stitch, the stitch was positioned at the middle of the specimens in the $\mathrm{M}$ and $\mathrm{V}$ series (Figure 1(a)), and $350 \mathrm{~mm}$ from one of the ends in the MV series (Figure 1(b)).

The precast units were reinforced with grade S460 longitudinal deformed bars and grade S240 stirrups arranged as shown in Figure 1. No non-prestressed reinforcement was provided to the in situ stitch. Eccentric prestressing was provided to the specimens in the $\mathrm{M}$ and MV series, with the tendon located at a depth of $133 \mathrm{~mm}$; specimens in the $\mathrm{V}$ series were concentrically prestressed. Grade 60 concrete with a mean compressive cube strength at 28 days of $60 \mathrm{MPa}$ was used for all specimens. Post-tensioning was carried out using a $12.9 \mathrm{~mm}$ diameter seven-wire steel strand.

The specimens are identified using the following convention: (series)-(stitch width)-(concrete grade)-(prestressing force)(bonded or unbonded, i.e. B or U). For example, M-50-60$100-\mathrm{B}$ denotes a specimen in the $\mathrm{M}$ series with a stitch width of $50 \mathrm{~mm}$, made with grade 60 concrete and prestressed to $100 \mathrm{kN}$ using a bonded tendon. A list of all the specimens tested is provided in Table 1 .

\section{Preparation of specimens}

For specimens having an in situ concrete stitch, the stitch was cast 1 week after the casting of the precast units. For specimens without an in situ concrete stitch, the second unit was matchcast against the first unit 1 week after the casting of the first unit.
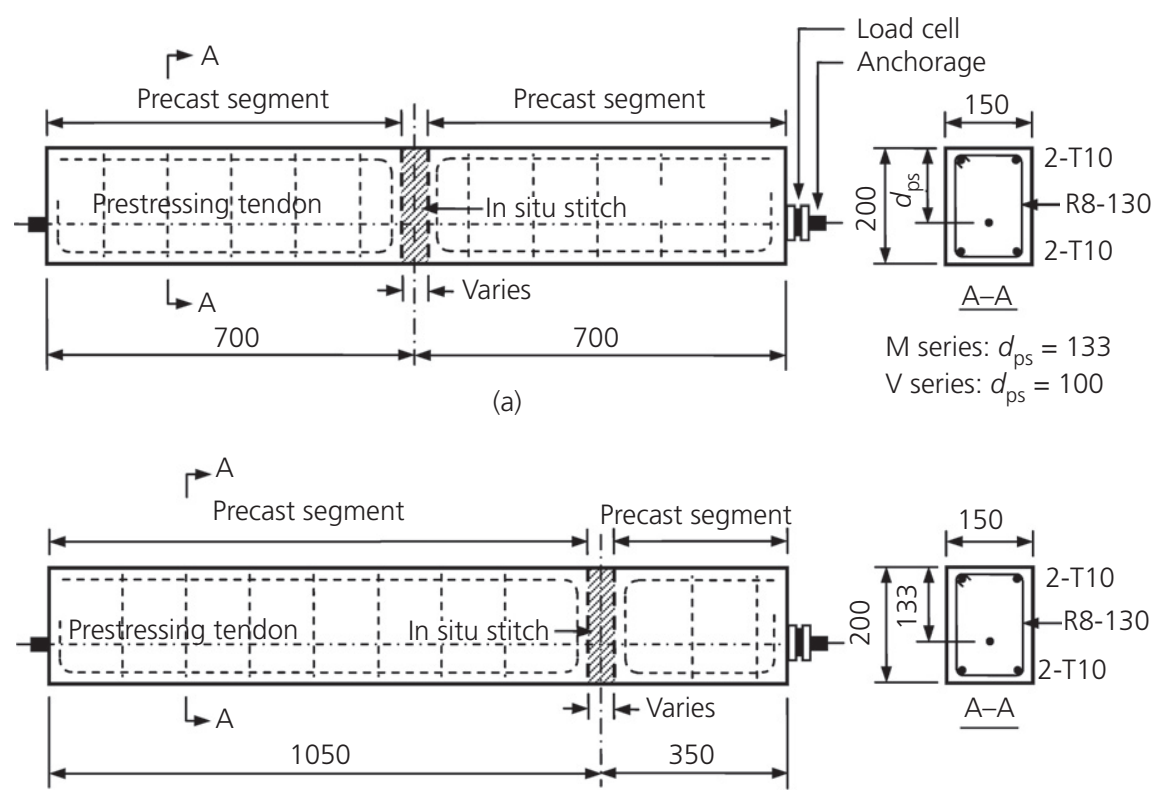

(b)

Figure 1. Specimens tested (dimensions in $\mathrm{mm}$ ): (a) $\mathrm{M}$ and $\mathrm{V}$

series; (b) MV series 


\begin{tabular}{|c|c|c|c|c|c|}
\hline Series & Specimen ID & Stitch width: mm & Concrete strength: MPa & Prestressing force: kN & Bonding of tendon \\
\hline \multirow[t]{5}{*}{ M } & M-0-60-100-U & 0 & 60 & 100 & Unbonded \\
\hline & M-50-60-100-U & 50 & 60 & 100 & Unbonded \\
\hline & M-100-60-100-U & 100 & 60 & 100 & Unbonded \\
\hline & M-50-60-100-B & 50 & 60 & 100 & Bonded \\
\hline & M-100-60-100-B & 100 & 60 & 100 & Bonded \\
\hline \multirow[t]{5}{*}{ V } & V-0-60-100-U & 0 & 60 & 100 & Unbonded \\
\hline & V-50-60-100-U & 50 & 60 & 100 & Unbonded \\
\hline & V-100-60-100-U & 100 & 60 & 100 & Unbonded \\
\hline & V-50-60-100-B & 50 & 60 & 100 & Bonded \\
\hline & V-100-60-100-B & 100 & 60 & 100 & Bonded \\
\hline \multirow[t]{5}{*}{ MV } & MV-0-60-100-U & 0 & 60 & 100 & Unbonded \\
\hline & MV-50-60-100-U & 50 & 60 & 100 & Unbonded \\
\hline & MV-100-60-100-U & 100 & 60 & 100 & Unbonded \\
\hline & MV-50-60-100-B & 50 & 60 & 100 & Bonded \\
\hline & MV-100-60-100-B & 100 & 60 & 100 & Bonded \\
\hline
\end{tabular}

Table 1. List of beam specimens tested

For unbonded specimens, prestressing was applied 28 days after casting the in situ stitch, and the loading test was subsequently performed on the same day. For bonded specimens, prestressing and grouting were performed 2 weeks after stitch casting after it was confirmed that the stitch had gained sufficient strength. A loading test was then performed $28 \mathrm{~d}$ after grouting.

The joint surface of precast concrete is sometimes treated to remove laitance for better bonding. In the experiment, the surface of the precast segment at the construction joint was scraped using a needle gun to remove the laitance and expose the coarse aggregates.

\section{Test setup}

Monotonic load testing was carried out using an Avery testing frame with a capacity of $1000 \mathrm{kN}$. The testing arrangements are illustrated in Figure 2. By loading the specimens as shown in Figures 2(a)-2(c), the stitch or the construction joint was subject to pure bending moment, pure shear or a combination of moment and shear, respectively.

The applied load was monitored by a load cell mounted against the actuator of the testing frame. Displacements were monitored at discrete locations along the beam by linear variable differential transformers (LVDTs) and the readings were recorded by a data logger. The variation in prestressing force with applied mass was monitored for unbonded specimens. As the tendon stress was assumed to be uniform along the tendon, the prestressing force could be measured by a load cell mounted at the anchorage. For bonded specimens, however, because the tendon stress was non-uniform, the method did not apply.

\section{Experimental results}

\section{Observations from experiment}

The typical flexural failure observed for specimens in the $\mathrm{M}$ series is illustrated in Figure 3. The numbers written on the specimen are the ram displacements (in $\mathrm{mm}$ ) corresponding to the extent of the cracks. All specimens in the M series showed similar crack propagation as in Figure 3, and this can be categorised into four different stages: (i) cracking was initiated at both construction joints; (ii) the cracks propagated vertically along the joints as the load increased; (iii) the cracks propagated longitudinally as they reached the compression zone, and the cracks along the joints in the tension zone opened, with typical widths of $2-3 \mathrm{~mm}$ at the soffit; and (iv) spalling and crushing of concrete occurred at the top. Regardless of whether a bonded or unbonded tendon was used, no major cracking was observed apart from cracks found along the joints and in the compression zone in the vicinity of the stitch. This cracking pattern is different from the one typically observed in prestressed concrete beams that have been continuously cast and reinforced under a similar loading pattern. In the latter case, a number of flexural cracks are usually present along the bonded beam, while fewer but wider cracks usually appear in unbonded beams (Mattock et al., 1971).

\section{Load-displacement response}

The load-displacement relationships of the bonded and unbonded specimens in the $\mathrm{M}, \mathrm{V}$ and $\mathrm{MV}$ series are plotted in Figures 4(a)-4(c). As the focus of the study was on the performance of in situ stitches normally located at midspan, where the flexural effect is dominant, the subsequent discussion mainly addresses the results obtained for the $\mathrm{M}$ series. Further discussion of the other two series can be found in Leung (2012). 


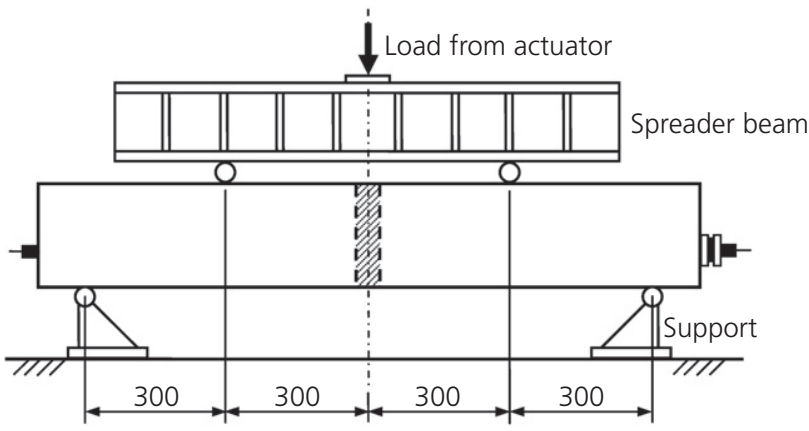

(a)

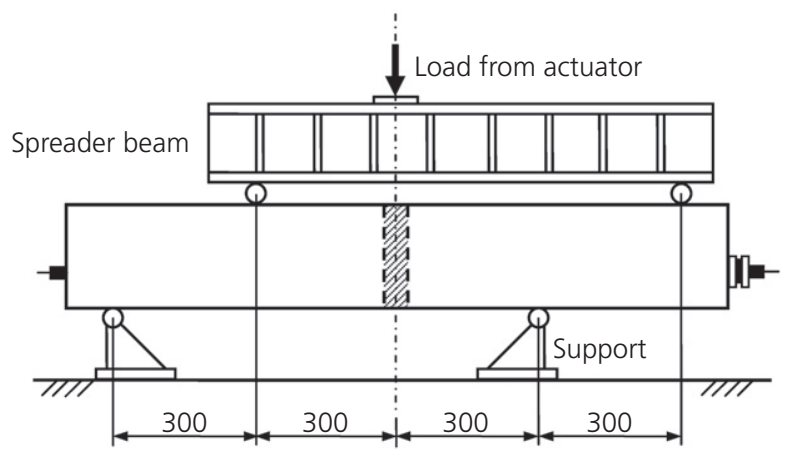

(b)

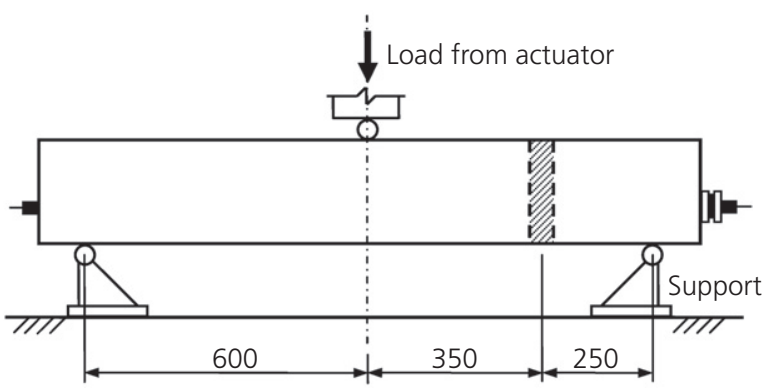

(c)

Figure 2. Setup of loading test for specimens (dimensions in $\mathrm{mm}$ ): (a) M series; (b) $V$ series; (c) MV series

The overall trend shown by the load-displacement relationships consists of an initial elastic branch, followed by another linear branch with reduced gradient, and finally a plateau, possibly ending with an abrupt drop corresponding to member failure. The transition from the elastic branch to the second linear branch corresponds to the initiation of cracking along the construction joints, while the plateau is attributed to further cracking, spalling of concrete in the compression zone and the prestressing tendons approaching their ultimate stress.

It can be seen from Figure 4(a) that, regardless of the stitch width or whether bonded or unbonded tendons are used, the elastic flexural stiffnesses are similar. The peak strengths of most specimens are more or less the same, varying from $80 \mathrm{kN}$

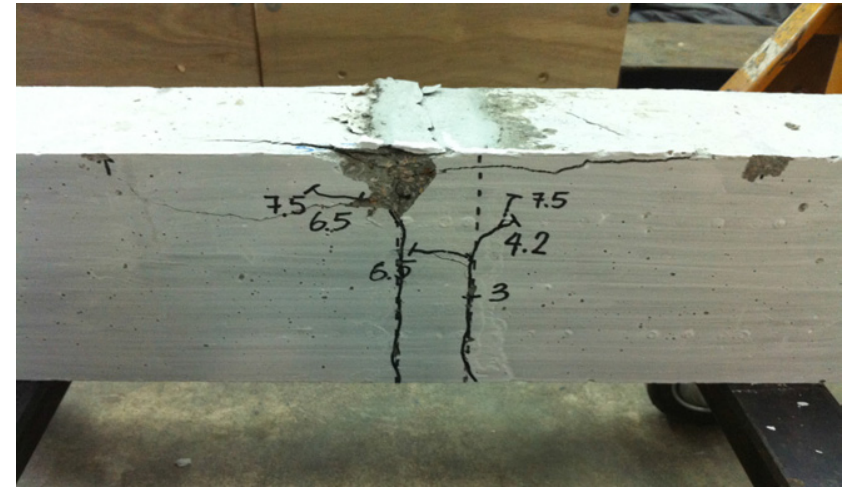

Figure 3. Typical failure mode of members with an in situ concrete stitch subject to pure bending moment

to $90 \mathrm{kN}$, with the exception of specimen $\mathrm{M}-100-60-100-\mathrm{B}$, which has a slightly higher peak strength of $105 \mathrm{kN}$. The plot shows little correlation between the peak strength and the stitch width, which suggests that the width of the stitch does not have a significant effect on the strength of the member within the range of stitch widths tested.

Figure 4(a) shows that within the pre-peak range the loaddisplacement relationships of the bonded specimens are close to each other, forming one band, and those of the unbonded specimens are also close to one another, forming another band. This reveals that the variation in stitch width has little effect on the load-displacement relationship. The figure also shows that the unbonded specimens tend to have higher strength than the bonded specimens from the elastic limit to the peak. This may be attributed to the prestressing loss in the bonded specimens, as they were tested approximately 28 days after grouting. Numerical analysis shows that a decrease in the prestressing force tends to reduce the member strength.

\section{Numerical analysis}

As only a limited number of values for each parameter could be measured experimentally, much of the study was carried out using finite-element analysis and the commercial software package MIDAS FEA (MIDAS Information Technology, 2008). Numerical models of the experimental specimens were constructed and calibrated against the experimental results. A parametric study was then performed using a broader range of values for each parameter.

\section{Modelling of the specimens and method of analysis}

Models of the specimens were constructed using four-node plane stress elements for concrete and truss elements and for prestressing tendons and non-prestressed reinforcement. Line interface elements were used to model the construction joints, while bond-slip interface elements were used to model the interface between the concrete and the prestressing tendon. 


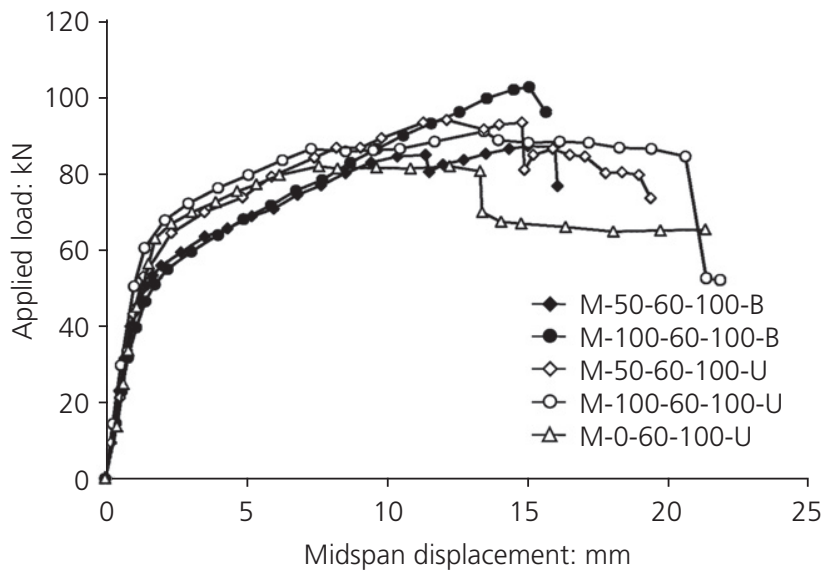

(a)

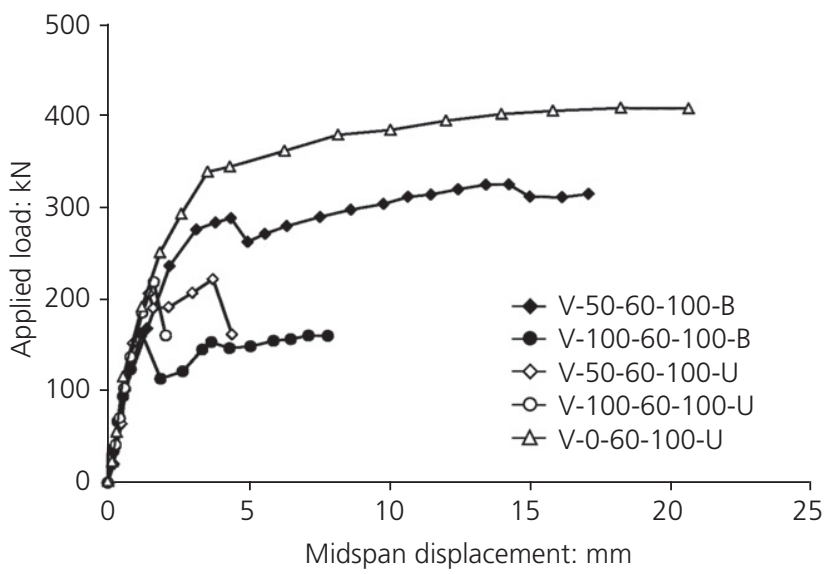

(b)

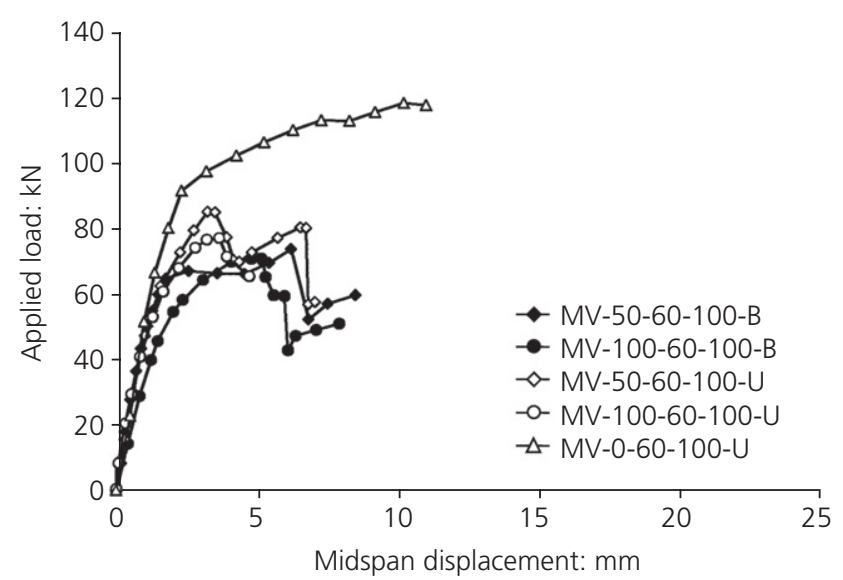

(c)

Figure 4. Experimental load-displacement curves for specimens: (a) M series; (b) $V$ series; (c) MV series

The constitutive models proposed by Attard and Setunge (1996) and Hordijk (1991) were adopted for concrete under uniaxial compression and tension, respectively. The post-crack shear behaviour of concrete was taken into account by applying a constant shear retention factor $\beta$ to the pre-crack shear

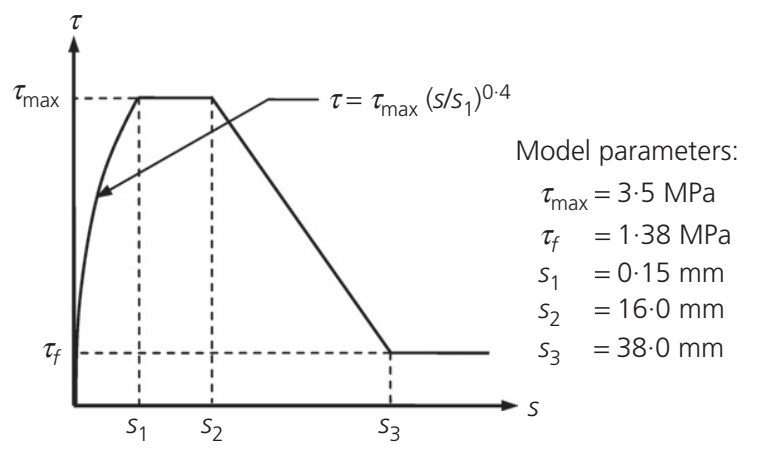

Figure 5. Bond-slip model adopted

modulus $G_{\mathrm{c}}$ in order to reduce the shear stiffness after cracking, thereby giving the post-crack shear modulus $G_{\mathrm{c}, \mathrm{cr}}$ as

1. $G_{\mathrm{c}, \mathrm{cr}}=\beta G_{\mathrm{c}}$

with $\beta$ taken as $0 \cdot 1$. This value is within the range of values suggested by Vecchio (2000). The constitutive model proposed by Menegotto and Pinto (1973) was used for prestressing steel, while the non-prestressed steel was assumed to be elastoplastic.

The interface element used for the construction joints was the discrete crack model contained within MIDAS FEA. A similar model was also adopted by Turmo et al. (2005) to simulate the behaviour of joints between precast concrete deck segments. The bond-slip relationship as given in the CEB-FIP Model Code (Comité Euro-International du Béton, 1993) was used to model the behaviour of the interface between the concrete and the bonded tendon, as shown in Figure 5, where $u$ is the slip of the tendon (in $\mathrm{mm}$ ) and $q$ is the bond stress (in $\mathrm{MPa}$ ). The values of model parameters suggested by Tabatabai and Dickson (1993) were used, and the finite-element analysis of prestressed concrete girders took into account the bond-slip relationship reported by Ayoub and Filippou (2010). For unbonded specimens, a small constant value of bond stress was assumed.

Staged nonlinear analysis was adopted to account for post-tensioning, where the tendon was first stressed and displacement was subsequently imposed. For bonded specimens, the bond stress of the bond-slip elements was adjusted in the staged analysis in order to model the process where the tendon was initially unbonded during stressing and subsequently bonded by grouting.

\section{Model calibration}

The models of specimens M-50-60-100 and M-100-60-100, bonded and unbonded, respectively, were calibrated against the experimental results to obtain the values of various empirical parameters, including the stiffness of interface elements, to be 
applied to all other models in the series. The experimental and numerical load-displacement relationships for these specimens are plotted in Figure 6, which reveals good agreement of peak strengths and overall trend.

\section{Parametric study}

A parametric study was carried out to examine further the effects of stitch width, prestressing force, concrete strength, bonding of the prestressing tendon and the provision of shear keys on the load-displacement relationships of members having an in situ concrete stitch. The effect of the prestressing force on crack development at the construction joint was also investigated.

The effect of providing shear keys to beam specimens was only examined numerically, not experimentally, in view of the large size of specimen required. Nevertheless, experimental testing on L-shaped specimens having stitches with shear keys subject to direct shear has been carried out and reported by the authors previously (Zeng et al., 2012). The configuration of the shear keys analysed was that given in the guideline of the

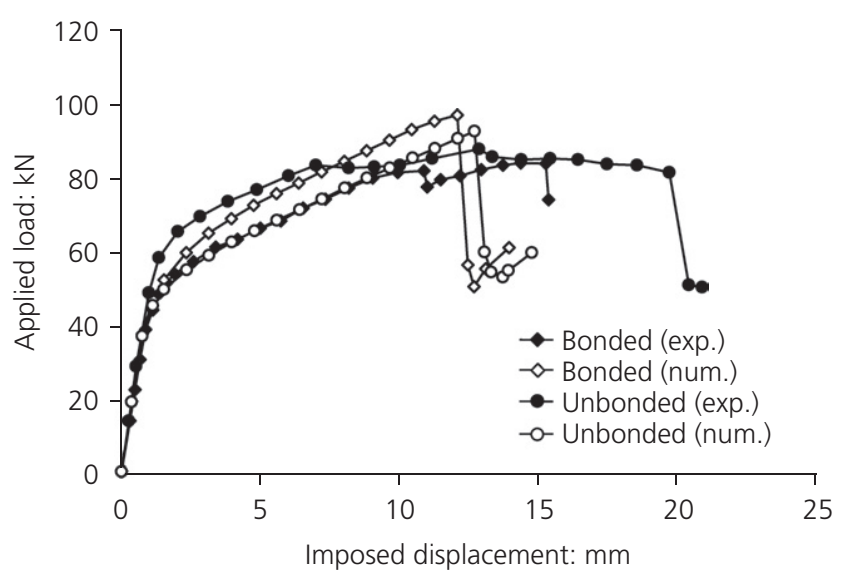

(a)

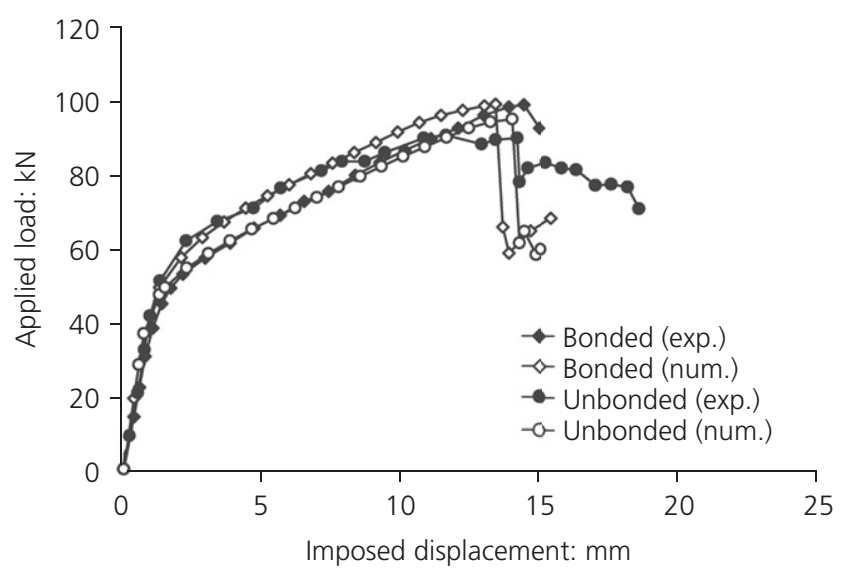

(b)

Figure 6. Experimental and numerical load-displacement response: (a) M-50-60-100; (b) M-100-60-100
American Association of State Highway and Transportation Officials (AASHTO, 1999), as illustrated in Figure 7.

In the parametric study, the models with stitches were divided into two groups, namely those without shear keys (plain stitches) and those with shear keys (keyed stitches). In each group, members with bonded and unbonded tendons were analysed. The ranges of values examined for the other parameters were: a stitch width of $50-150 \mathrm{~mm}$; prestressing force of 40-120 kN; and concrete grade of 40-80 MPa.

\section{Results and discussion}

\section{Effects of stitch width}

Members having a concrete strength of $60 \mathrm{MPa}$ and prestressing force of $100 \mathrm{MPa}$ were studied. The load-displacement relationships of bonded and unbonded members having different stitch widths are plotted in Figures 8(a) and 8(b) for members with plain and keyed stitches, respectively. For each group of bonded and unbonded members, the load-displacement curves of members with different stitch widths are nearly identical except for a minor difference in peak strength. This suggests that for stitch widths in the range $50-150 \mathrm{~mm}$ the stitch width has little effect on the load-displacement behaviour and the peak strength, whether plain or keyed stitches are provided. However, the bonded members are stronger.

\section{Effects of prestressing force}

Members having a stitch width of $50 \mathrm{~mm}$ and a concrete strength of $60 \mathrm{MPa}$ were then studied. The load-displacement
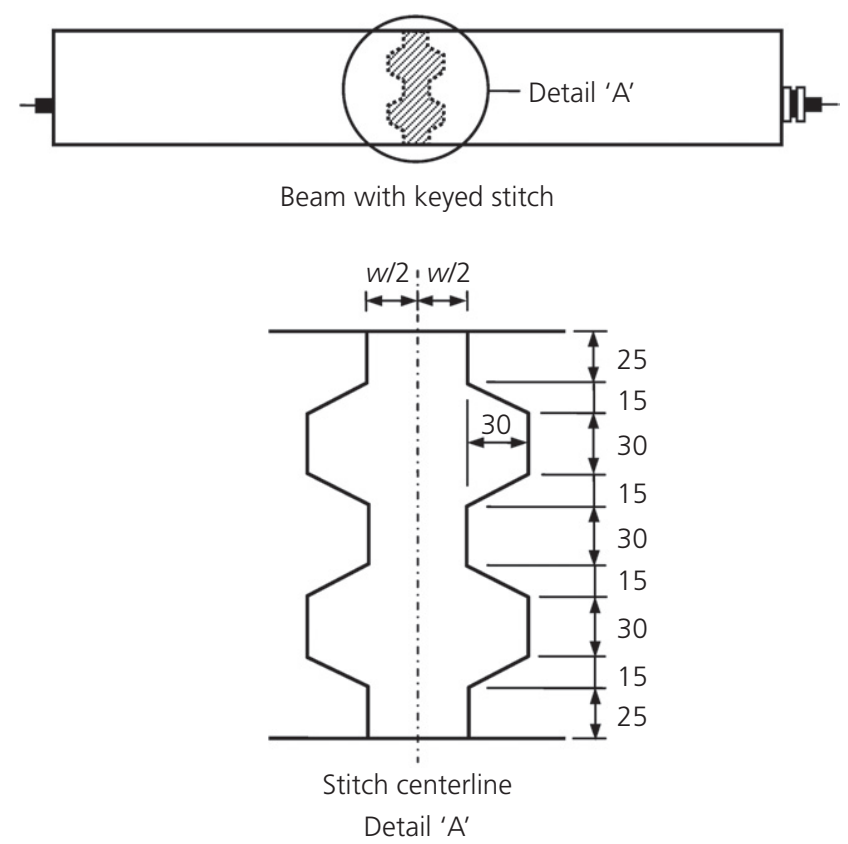

Figure 7. Configuration of shear keys (dimensions in $\mathrm{mm}$ ): (a) M-50-60-100; (b) M-100-60-100 


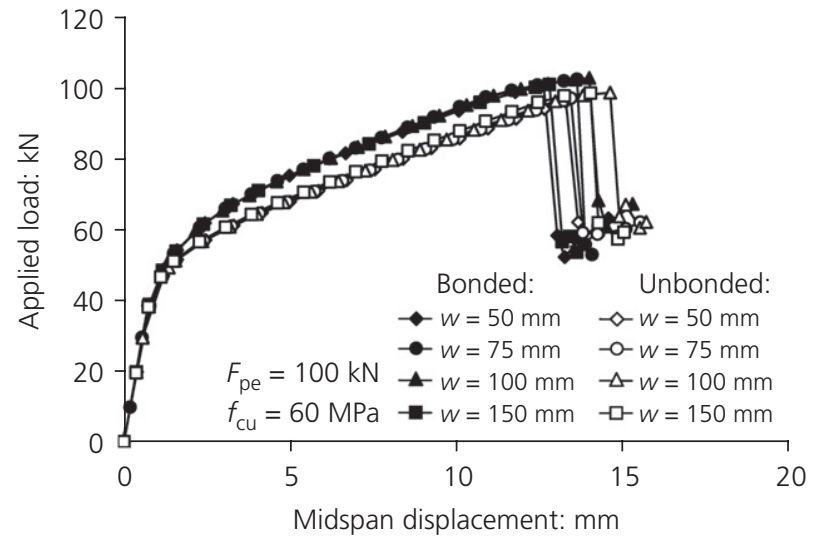

(a)

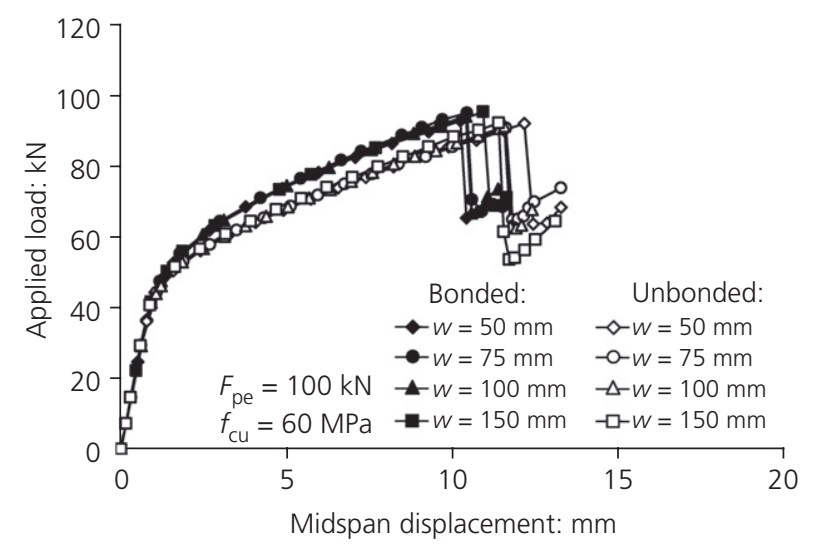

(b)

Figure 8. Effects of stitch width on the load-displacement relationship of bonded and unbonded members with (a) plain stitch and (b) keyed stitch

relationships of bonded and unbonded members at different effective prestressing forces are plotted in Figures 9(a) and 9(b) for members with plain and keyed stitches, respectively. The following are observed as the prestressing force increases: (i) the elastic limit increases; (ii) the member strength increases at the same displacement beyond the elastic limit; (iii) the peak strength increases; and (iv) the displacement at which peak strength occurs decreases and there is a reduction in deformability. Moreover, the strengths of bonded members are consistently higher than those of unbonded members beyond the elastic range for all cases of prestressing force applied. In Figure 9(a), an abrupt drop in the load-displacement relationship is observed for the unbonded member with a prestressing force of $120 \mathrm{kN}$. The residual strength that this member attained following the drop was much less than that attained by other members, but the reason for this is unclear.

To conclude, the increase in the prestressing force can increase the strength of members having plain or keyed stitches but the deformability simultaneously decreases, especially for members with keyed stitches.

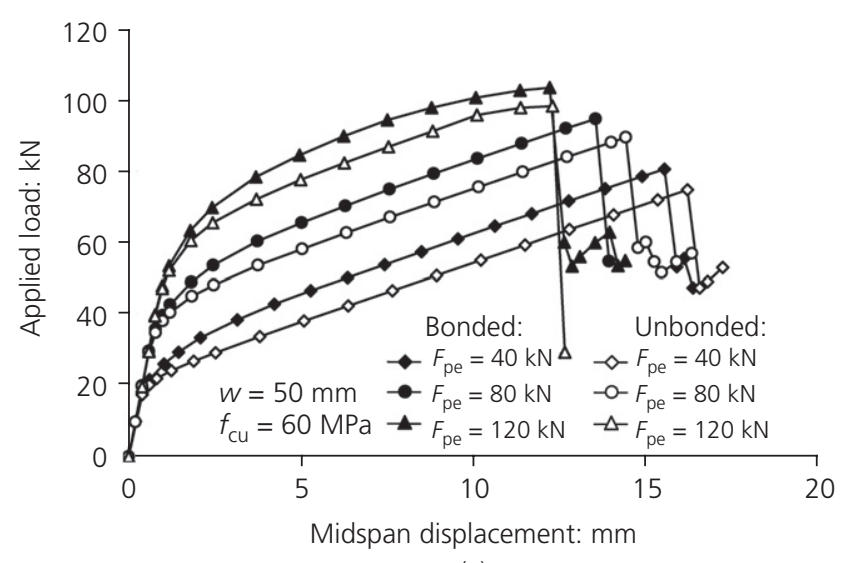

(a)

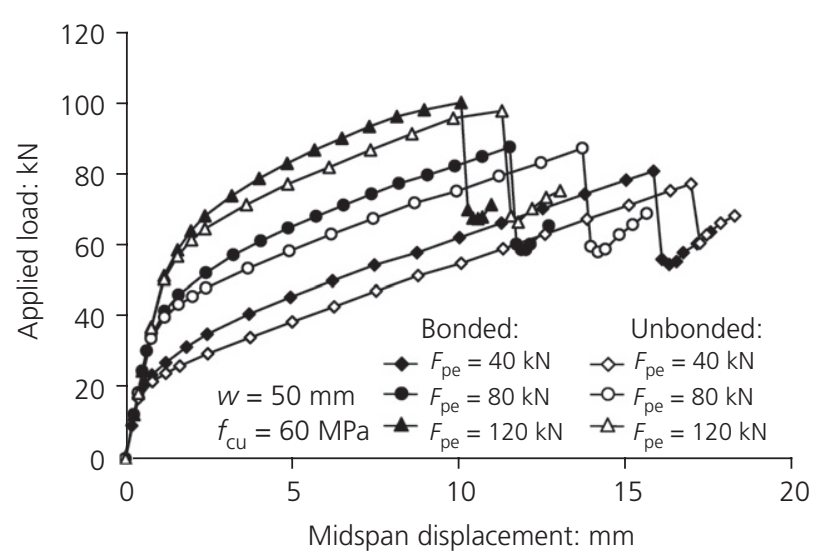

(b)

Figure 9. Effects of prestressing force on the load-displacement relationship of bonded and unbonded members with (a) a plain stitch and (b) a keyed stitch

\section{Effects of concrete strength}

Members with a stitch width of $50 \mathrm{~mm}$ and a prestressing force of $100 \mathrm{kN}$ were studied next. The load-displacement relationships of bonded and unbonded members having different concrete strengths are plotted in Figures 10(a) and 10(b) for members with plain and keyed stitches, respectively. Interestingly, all the data points for the bonded members before reaching the peak strength fall on one curve, while those for the unbonded members fall on another. The peak strength for each of the bonded and unbonded groups occurs at larger displacement as the concrete strength increases. Therefore, the increase in concrete strength has little effect on the trend of the load-displacement curve, but will increase the peak strength and the corresponding displacement. This property should be noted in case it is necessary to provide a structure with a certain degree of deformability.

\section{Effects of shear keys}

The members studied had a stitch width of $50 \mathrm{~mm}$, a concrete strength of $60 \mathrm{MPa}$ and a prestressing force of $100 \mathrm{kN}$. 


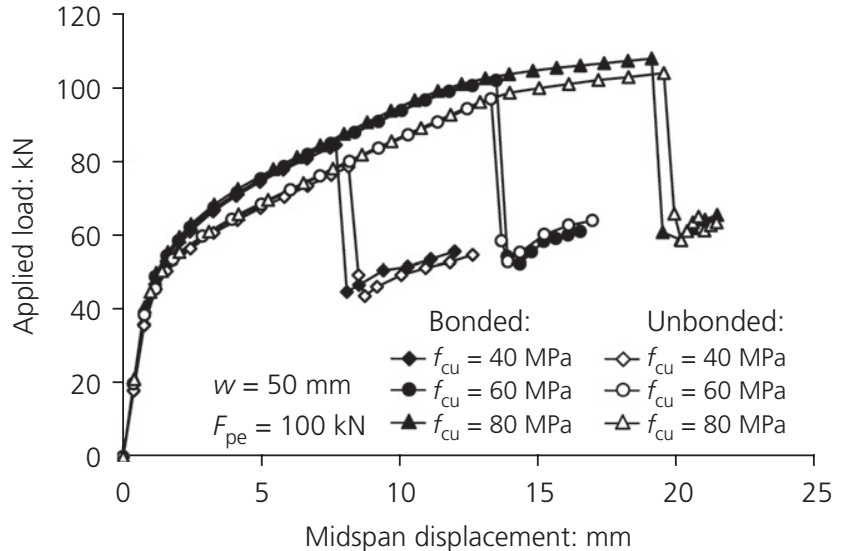

(a)

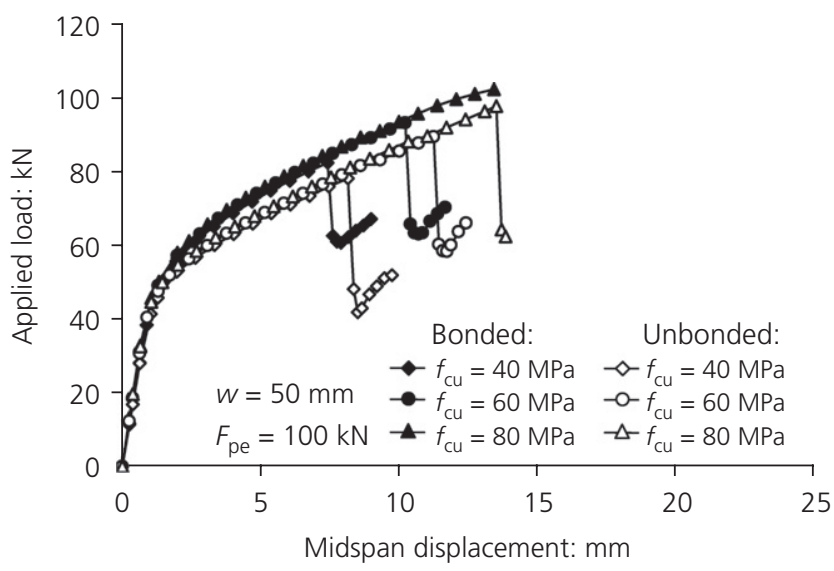

(b)

Figure 10. Effects of concrete strength on the load-displacement relationship of bonded and unbonded members with (a) a plain stitch and (b) a keyed stitch

The load-displacement relationships of bonded and unbonded members with plain and keyed stitches are plotted together in Figure 11. Obviously the provision of shear keys has little effect on the overall trend of the load-displacement behaviour. The peak strengths attained by members with plain and keyed stitches are more or less the same: the peak strengths for bonded members with plain and keyed stitches are 101 and $93 \mathrm{kN}$, respectively, while those for unbonded members with plain and keyed stitches are 96 and $92 \mathrm{kN}$, respectively. However, the deformability reduces when shear keys are provided. Similar observations are made when Figures 8 (a) and 8 (b), Figures 9(a) and 9(b) and Figures 10(a) and 10(b) are compared, implying that the provision of shear keys has relatively little effect on the peak strengths, but the effect on deformability is more significant. Deformability decreases with the provision of shear keys, possibly because of stress concentration at the corners and roots of shear keys, which may trigger fracturing. Therefore, due to stress concentration, the

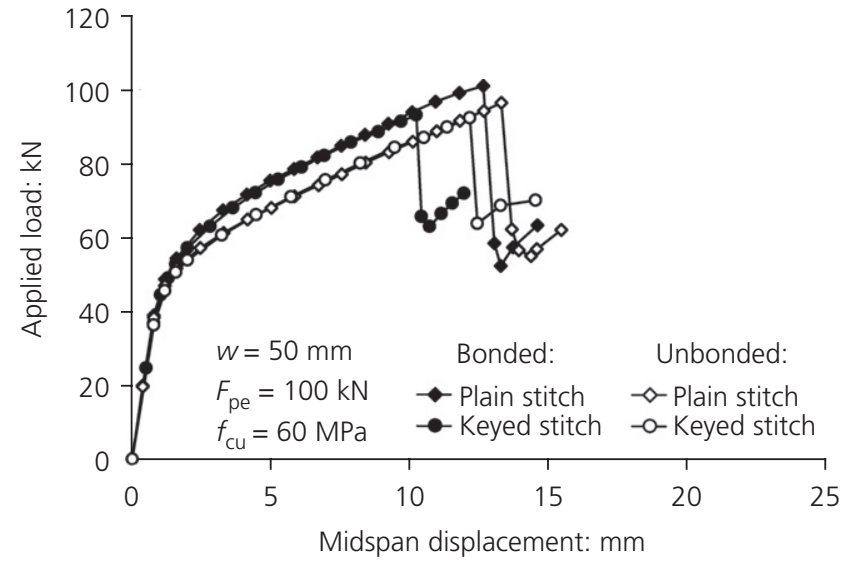

Figure 11. Effects of shear keys on the load-displacement relationship of bonded and unbonded members

concrete of a keyed stitch in the compression zone will fail sooner than that of a plain stitch.

The reduction in deformability with the provision of shear keys is also larger at higher prestressing force and concrete strength. By comparing the plots for bonded members in Figures 9(a) and 9 (b), the displacement at peak strength reduces from 15.8 to $15.5 \mathrm{~mm}$ when a relatively low prestressing force of $40 \mathrm{kN}$ is applied, while the displacement at peak strength reduces from $12 \cdot 2$ to $10 \mathrm{~mm}$ when the prestressing force increases to $120 \mathrm{kN}$. Comparison between Figures 10(a) and 10(b) reveals that the provision of shear keys to bonded members has little effect on the displacement at peak strength when a relatively low concrete strength of $40 \mathrm{MPa}$ is used, but the displacement reduces considerably, from $19 \cdot 1$ to $13 \cdot 4 \mathrm{~mm}$, when the concrete strength is increased to $80 \mathrm{MPa}$. As the prestressing force increases, the stress concentration becomes more significant, and therefore fracturing of the stitch in the compression zone occurs at a lower displacement. Moreover, as the concrete strength increases, the concrete becomes more brittle and more sensitive to the detrimental effect of stress concentration.

To conclude, while shear keys are useful in enhancing shear strength, their provision has little benefit for strength improvement when the stitch is subjected to pure flexure. Moreover, the introduction of stress concentration by the shear keys can also reduce the deformability of the members under flexure.

\section{Effects of prestressing force on crack width at construction joints}

As mentioned earlier, members with in situ concrete stitches have noticeable cracks at the construction joints only. As the concentration of cracking leads to the concentration of curvature at the joints, the crack widths at the construction joints may become excessive as loading increases. Moreover, the concentration of curvature in beams having an in situ stitch may 


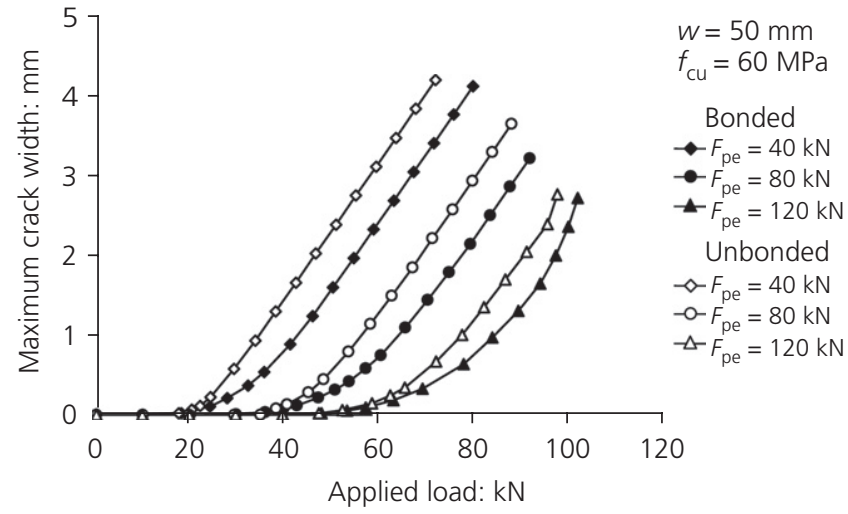

Figure 12. Effects of prestressing force on maximum crack width at the construction joints

result in cracks that are wider than those found in beams that have been continuously cast and reinforced at the same applied loading, as the latter have less concentration of curvature until the formation of the plastic hinge. Thus beams with in situ stitches are more prone to violating the crack limits imposed by most codes of practice. Excessive crack width can also lead to the intrusion of water or other detriments that can damage the tendons and cause serviceability problems. One preventive measure is to increase the level of prestress. Therefore, it is worth examining the effects of prestressing force on the development of crack width at the construction joints.

The variation in the maximum crack width at the construction joint with applied load is plotted in Figure 12 for different prestressing forces and for both bonded and unbonded members with a plain stitch. The maximum crack width is taken as the width of the crack at the soffit. The joint remains closed when the value of the maximum crack width is zero. The endpoint of each curve corresponds to the state at which the peak strength of the member is reached. Evidently the load that initiates cracking increases as the prestressing force increases. Once cracking occurs, the width of the crack increases rapidly. Under the same applied load, unbonded members have wider cracks than bonded members, as the bonded tendon can develop a larger clamping force across the construction joint than can the unbonded tendon, and thus requires a larger load to widen the crack further.

Codes of practice usually impose allowable limits on maximum crack width in member design. For instance, Eurocode 2 (European Committee for Standardization, 2004) allows a maximum crack width of up to 0.2 and $0.4 \mathrm{~mm}$ for bonded and unbonded members, respectively, while the crack width control in the ACI Code (ACI, 2005) is derived based on a maximum crack of $0.4 \mathrm{~mm}$. Figure 12 shows that, when a bonded member is prestressed to $40 \mathrm{kN}$, the maximum crack width can reach $4.2 \mathrm{~mm}$ when a load of $80 \mathrm{kN}$ is applied.
If the service load is roughly taken as one-third of the ultimate design load and if the ultimate load is $80 \mathrm{kN}$, the member has a service load of approximately $27 \mathrm{kN}$, at which the maximum crack width is approximately $0.5 \mathrm{~mm}$, a value that exceeds most code limits. With the increase in prestressing force, the problem of excessive cracking will be less likely to occur. It is recommended that in the design of prestressed concrete structures with an in situ stitch, class 1 or full prestressing is adopted for control of crack width at the serviceability limit state.

\section{Conclusions}

To study the performance of in situ stitches in precast concrete segmental bridges, both experimental and numerical studies of concrete beams with in situ stitches were conducted. A parametric study was carried out to examine the effects of stitch width, prestressing force, concrete strength, bonding of the tendons and provision of shear keys on the load-displacement relationships of the members. The effect of shear keys on crack width development was also examined. The following conclusions have been drawn:

(a) Cracking tends to initiate along the construction joints at the in situ stitch, while tensile cracking elsewhere is less noticeable.

(b) The effects of stitch width in its normal range on the peak strength and load-displacement response of the member are insignificant.

(c) An increase in effective prestress increases the elastic limit, the member strength under the same deformation and the peak strength, but tends to reduce deformability.

(d) Variation in concrete strength has little effect on the trend shown by the load-displacement response, but the peak strength and the corresponding displacement increase with concrete strength.

(e) When the stitch is subject to essentially pure flexure, provision of shear keys has little benefit on strength improvement and may introduce stress concentration, which can adversely affect deformability.

(f) Bonded members tend to have higher strength as well as better crack control at the construction joint than unbonded members.

(g) In the design of members with an in situ stitch, class 1 or fully prestressed concrete structures should be adopted for better crack control at the construction joint.

\section{Acknowledgement}

This study was supported by the Research Grants Council of the Hong Kong Special Administrative Region, China (RGC Project No. HKU 710807E), and the Small Project Funding and the HKU SPACE Research Fund of The University of Hong Kong. 


\section{REFERENCES}

AASHTO (American Association of State Highway and Transportation Officials) (1999) Guide Specifications for Design and Construction of Segmental Concrete Bridges. AASHTO, Washington, DC, USA.

ACI (2005) Committee 318: Building Code Requirements for Reinforced Concrete (ACI 218-05) and Commentary (ACI318-R-05). American Concrete Institute, Farmington Hills, MI, USA.

Attard MM and Setunge S (1996) The stress-strain relationship of confined and unconfined concrete. ACI Materials Journal 93(5): 432-442.

Ayoub A and Filippou FC (2010) Finite-element model for pretensioned prestressed concrete girders. Journal of Structural Engineering 136(4): 401-409.

Buyukozturk O, Bakhoum MM and Beattie SM (1990) Shear behaviour of joints in precast concrete segmental bridges. Journal of Structural Engineering 116(12): 3380-3401.

Comité Euro-International du Béton (1993) CEB-FIP Model Code 1990. Thomas Telford, London, UK.

ECl (European Committee for Standardization) (2004) Eurocode 2: Design of concrete structures - Part 1-1: General rules and rules for buildings. European Committee for Standardization, Brussels, Belgium.

Hewson N (1992) The use of dry joints between precast segments for bridge decks. Proceedings of the ICE-Civil Engineering 92(4): 177-184, http://dx.doi.org/10.1680/icien. 1992.21499.

Hordijk DA (1991) Local Approach to Fatigue of Concrete. Delft University of Technology, Delft, the Netherlands.

Issa MA and Abdalla HA (2007) Structural behaviour of single key joints in precast concrete segmental bridges. Journal of Bridge Engineering 12(3): 315-324.

Koseki K and Breen JE (1983) Exploratory Study of Shear Strength of Joints for Precast Segmental Bridges. Texas State Department of Highways and Public Transportation, Austin, Texas, USA, Research Report 248-1.

Leung CCY (2012) Performance of In-situ Concrete Stitches in Precast Concrete Segmental Bridges. PhD thesis, The University of Hong Kong, Hong Kong.
Mattock AH, Yamazaki J and Kattula BT (1971) Comparative study of prestressed concrete beams, with and without bond. ACI Journal 68(2): 116-125.

Megally S, Seible F and Dowell RK (2003) Seismic performance of precast segmental bridges: segment-to-segment joints subjected to high flexural moments and low shears. PCI Journal 28(2): 80-96.

Menegotto M and Pinto PE (1973) Method of analysis for cyclically loaded R.C. plane frames. Proceedings of the Symposium on Resistance and Ultimate Deformability of Structures Acted on by Well-Defined Repeated Loads, IABSE, Lisbon, Portugal, pp. 15-22.

MIDAS Information Technology (2008) Analysis and Algorithm. MIDAS Information Technology, Seoul, South Korea.

Moreton AJ (1981) Epoxy glue joints in precast concrete segmental bridge construction. Proceedings of the ICE - Design and Construction 70(1): 163-177, http://dx.doi.org/10.1680/iicep.1981.1963.

Tabatabai H and Dickson TJ (1993) The history of the prestressing strand development length equation. PCI Journal 38(6): 64-75.

Takebayashi T, Deeprasertwong K and Leung YW (1994) A fullscale destructive test of a precast segmental box girder bridge with dry joints and external tendons. Proceedings of the ICE - Engineering Structures and Buildings 104(3): 297-315, http://dx.doi.org/10.1680/istbu.1994.26780.

Turmo J, Ramos G and Aparicio AC (2005) FEM study on the structural behaviour of segmental concrete bridges with unbonded prestressing and dry joints: simply supported bridges. Engineering Structures 27(11): 1652-1661.

Turmo J, Ramos G and Aparicio AC (2006) Shear strength of dry joints of concrete panels with and without steel fibres - application to precast segmental bridges. Engineering Structures 28(1): 23-33.

Vecchio FJ (2000) Analysis of shear-critical reinforced concrete beams. ACI Structural Journal 97(1): 102-110.

Zeng Y, Au FTK and Leung CCY (2012) Analysis of in-situ stitches in precast concrete segmental bridges. IES Journal Part A: Civil \& Structural Engineering 5(1): 1-15.

Zhou X, Mickleborough N and Li Z (2005) Shear strength of joints in precast concrete segmental bridges. ACI Structural Journal 102(1): 3-11.

\section{WHAT DO YOU THINK?}

To discuss this paper, please submit up to 500 words to the editor at journals@ice.org.uk. Your contribution will be forwarded to the author(s) for a reply and, if considered appropriate by the editorial panel, will be published as a discussion in a future issue of the journal. 